\title{
Origin and significance of intra- basement seismic reflections offshore western Norway
}

\author{
Matthew T. Reeve \\ Rebecca E. Bell \\ Christopher A-L. Jackson \\ Department of Earth Science and Engineering, Imperial College, Prince Consort Road, South \\ Kensington Campus, Imperial College, London, SW7 2BP, UK
}

\section{Supplementary material S1}

This supplementary material contains an explanation of the velocity model used to depth convert interpretations made from time-migrated seismic reflection data.

Time-depth data from wells 35/9-2 and 36/7-1 (See Fig. 1B) are shown in Fig. S1. Both wells show almost identical relationships between TWT and depth to depths of $\sim 2.5 \mathrm{~km}$. A best fit second-order polynomial trend line has been fit to these data and this relationship has been used to depth convert horizon interpretations down to the acoustic basement.

$\mathrm{d}=275.92 \mathrm{t}^{2}+481.77 \mathrm{t}+76.833 \quad \mathrm{R}^{2}=0.9991 \quad \mathrm{~d}=\mathrm{depth}, \mathrm{t}=$ TWT

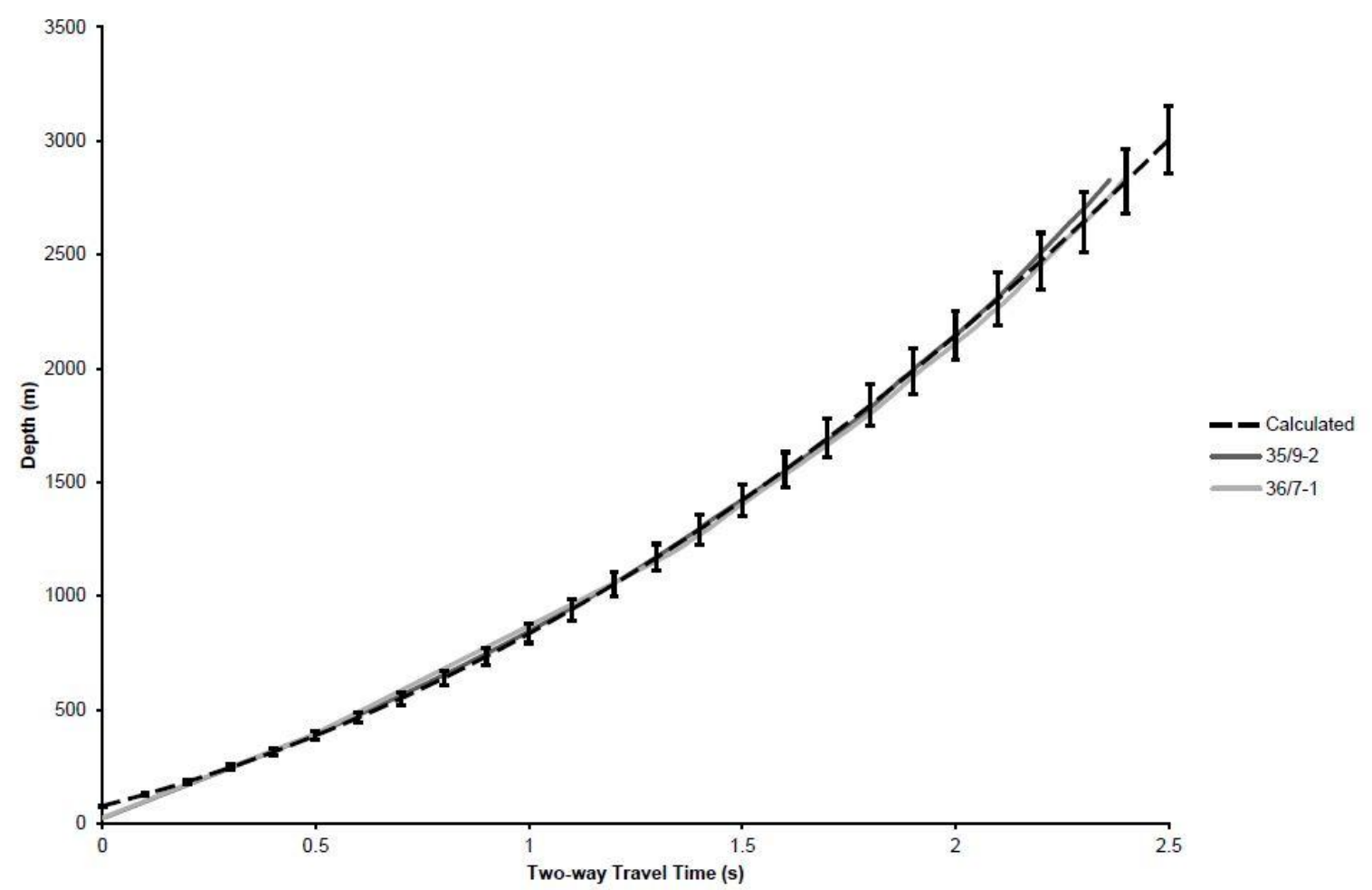

Fig. S1 Time-depth data for wells 35/9-2 and 36/7-1. See Fig. 1B for location 
In order to depth convert intrabasement reflections interpretations, firstly the depth to the basement was depth converted using the polynomial time-depth relationship described above. Secondly a constant P-wave seismic velocity of $6 \mathrm{~km} / \mathrm{s}$ was assigned to the basement following studies by Goff \& Holliger, 1999. The interpreted TWT between the intrabasement reflections and basement was then depth converted using a constant velocity of $6 \mathrm{~km} / \mathrm{s}$, and this depth was added to the basement depth to get the total depth to the intrabasement reflection. Basement rock velocities of $5.5 \mathrm{~km} / \mathrm{s}$ and $6.5 \mathrm{~km} / \mathrm{s}$ were also considered. The variations in depth to intrabasement reflections and the dip angles of these surfaces caused by these variations in velocity were found to be less than $5 \%$. 